\title{
Anatomy, Biogenesis and Regeneration of Salivary Glands
}

\author{
Kyle V. Holmberg • Matthew P. Hoffman
}

Matrix and Morphogenesis Section, Laboratory of Cell and Developmental Biology, National Institute of Dental and Craniofacial Research, National Institutes of Health, Bethesda, Md., USA

\begin{abstract}
An overview of the anatomy and biogenesis of salivary glands is important in order to understand the physiology, functions and disorders associated with saliva. A major disorder of salivary glands is salivary hypofunction and resulting xerostomia, or dry mouth, which affects hundreds of thousands of patients each year who suffer from salivary gland diseases or undergo head and neck cancer treatment. There is currently no curative therapy for these patients. To improve these patients' quality of life, new therapies are being developed based on findings in salivary gland cell and developmental biology. Here we discuss the anatomy and biogenesis of the major human salivary glands and the rodent submandibular gland, which has been used extensively as a research model. We also include a review of recent research on the identification and function of stem cells in salivary glands, and the emerging field of research suggesting that nerves play an instructive role during development and may be essential for adult gland repair and regeneration. Understanding the molecular mechanisms involved in gland biogenesis provides a template for regenerating, repairing or reengineering diseased or damaged adult human salivary glands. We provide an overview of 3 general approaches currently being developed to regener-
\end{abstract}

ate damaged salivary tissue, including gene therapy, stem cell-based therapy and tissue engineering. In the future, it may be that a combination of all three will be used to repair, regenerate and reengineer functional salivary glands in patients to increase the secretion of their saliva, the focus of this monograph.

(c) 2014 S. Karger AG, Basel

\section{Salivary Gland Anatomy}

The three pairs of major salivary glands in humans are the parotid (PG), submandibular (SMG) and sublingual glands (SLG). The anatomical architecture of all three glands is essentially the same: an arborized ductal structure that opens into the oral cavity with secretory end pieces, the acini, producing saliva. The acinar cells are surrounded by an extracellular matrix, myoepithelial cells, myofibroblasts, immune cells, endothelial cells, stromal cells and nerve fibers. The ducts transport and modify the saliva before it is excreted into the oral cavity through the excretory duct. Stensen's duct is the main excretory duct of the PG and enters the oral cavity in the buccal mu- 


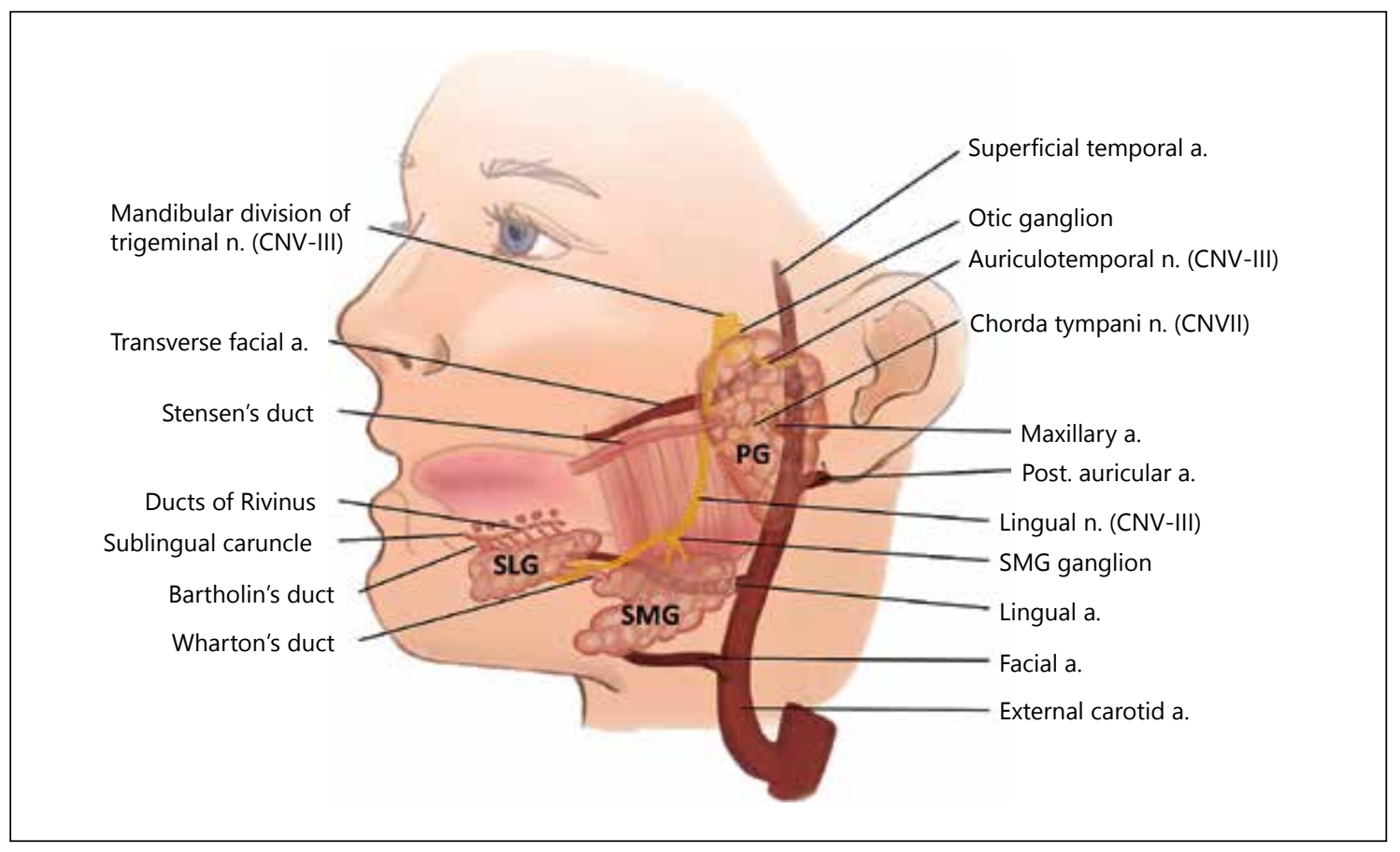

Fig. 1. Overview of salivary gland anatomy. The three major salivary glands are the PG, SMG and SLG. Stensen's and Wharton's ducts are the main excretory ducts of the PG and SMG, respectively. Blood supply is mainly provided to the PG by the transverse facial artery and to the SMG by the facial artery. Parasympathetic innervation arises from postganglionic nerves from the otic and submandibular ganglia. The otic ganglion is associated closely with the mandibular division of the trigeminal nerve (CNV-III), and the submandibular ganglion is next to the lingual nerve. Sympathetic postganglionic nerves (not shown) arise from the superior cervical ganglion and innervate the glands along blood vessels.

cosa near the second maxillary molar after crossing the masseter muscle and penetrating through the buccinator muscle. Wharton's duct is the main excretory duct of the SMG, which opens into the oral cavity under the tongue by the lingual frenum at a structure called the sublingual caruncula. The SLG has small ducts called ducts of Rivinus and a common duct, Bartholin's duct, which connects with Wharton's duct at the sublingual caruncula (fig. 1).

The major salivary glands are highly vascularized and innervated. The transverse facial artery emerges from the superficial temporal artery to provide blood supply to the PG and traverses along Stensen's duct. The facial artery, a branch of the external carotid artery, brings blood supply to the SMG and passes through the gland capsule before crossing the inferior border of the mandible. The facial nerve (cranial nerve, $\mathrm{CN}, \mathrm{VII}$ ) is closely associated with the PG capsule, which also contains lymph nodes and is continuous with the superficial layer of deep cervical fascia. Facial nerve injury and resulting hemifacial paralysis constitute a significant risk of surgeries for PG tumor resection. The lingual nerve is closely associated with Wharton's duct in the floor of the mouth. Therefore, lingual nerve injury is a possible complication of surgical exploration of the floor of the mouth for removal of salivary stones. The capsule of the SMG is part of the superficial layer of deep cervical fascia. Lymph nodes are not within the capsule of the gland but are adjacent in 
the submandibular triangle, an anatomic region formed by the boundaries of the inferior border of the mandible and anterior and posterior bellies of the digastric muscle $[1,2]$.

Saliva has multiple functions that include lubrication of the oral cavity to enable talking, swallowing, eating, tasting, dental health and maintaining oral homeostasis, while also providing protective functions and aiding in digestion. Many of these important functions will be covered in the papers by Lindh et al., van 't Hof et al., Brand et al., Neyraud and Yakubov [this vol., pp. $30-39,40-51,52-60,61-70,71-87]$ of this monograph. The different types of acinar cells in each gland result in different types of saliva. The PG is composed of serous acini and produces watery serous saliva. The SMG and SLG are both mixed glands containing both mucous and serous acini. The SMG has a majority of serous acinar cells with fewer mucous cells, whereas the SLGs are composed of a majority of mucous acinar cells. The major salivary glands in a healthy adult produce over $90 \%$ of saliva. In addition, there are minor glands, which are found in the palate and are widely distributed across the oral mucosa [3]. The secretion of saliva is stimulated by both the parasympathetic and sympathetic branches of the autonomic nervous system, and will be covered in the paper by Proctor and Carpenter [this vol. pp. 14-29] in this monograph.

The anatomy of the autonomic innervation of the major salivary glands is important to understand autonomic effects on not only salivation, but also biogenesis [4]. Briefly, parasympathetic stimulation results in serous, or watery, salivary secretion and ion secretion, whereas sympathetic stimulation increases the secretion of proteins. The cell bodies of the parasympathetic nerves that stimulate the PG are near the gland in the otic ganglion. The PG is innervated by postganglionic fibers that join the auriculotemporal nerve of the cranial nerve (CNV-III) [5, 6]. The cell bodies of the parasympathetic nerves that stimulate the SMG and SLG are located in the submandibular ganglia,

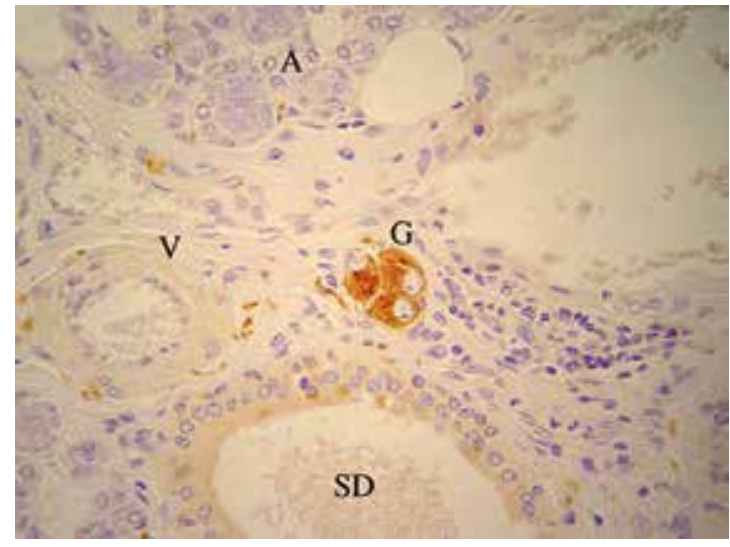

Fig. 2. The human SMG contains small ganglia within the gland stroma. Three synaptophysin-positive nerve cell bodies are arranged in a small ganglion (G) near acini $(A)$, a striated duct (SD) and a blood vessel (V). Figure from figure 3 in Tosios et al. [9].

which are within the gland. The SMG and SLG are innervated by postganglionic fibers that stimulate saliva secretion and innervate myoepithelial cells [7]. The submandibular ganglia's preganglionic parasympathetic fibers are carried by the chorda tympani of CNVII, which joins the lingual nerve of CNV-III in the infratemporal fossa and then synapses at the submandibular ganglia $[5,8]$. Importantly, there are also nerve cell bodies and small ganglia within the stroma of the SMG [9], although the functional significance of these ganglia is not clear (fig. 2). Interestingly, when SMG autotransplantation is used to treat absolute tear deficiency, the transplants show increasing secretory activity with time. The SMG autografts remain functionally viable due to survival of parasympathetic ganglia within the gland and sympathetic reinnervation in transplanted gland tissue [10].

In contrast to the parasympathetic nerves, the cell bodies of the sympathetic nerves are located in the superior cervical ganglion in the neck, and postganglionic fibers innervate the salivary glands along the blood vessels, which branch from the carotid plexus of the external carotid artery [8]. Sympathetic innervation is important for salivary 
secretion and influences local inflammation [11, 12]. While it is clear that the autonomic nervous system is essential for adult salivary gland secretion [13], only more recently has it been shown how parasympathetic innervation is critical for the biogenesis of mouse salivary glands [14]. The interactions between the epithelium and nerves studied in mouse salivary glands may have implications for the regeneration of human salivary glands [13-16].

A description of salivary gland innervation also requires mention of the neurotransmitters that are involved in neuronal function. The neurotransmitter acetylcholine signals at the synapse of pre- and post-ganglionic parasympathetic and preganglionic sympathetic nerves and activates muscarinic receptors in the salivary glands via postganglionic parasympathetic fibers. Noradrenaline from postganglionic sympathetic fibers activates adrenergic receptors. Other neurotransmitters have roles in salivary gland function, such as vasoactive intestinal peptide, encephalin, substance $\mathrm{P}$, neuropeptide $\mathrm{Y}$, neurokinin A, pituitary adenylate cyclase-activating peptide, neuronal nitric oxide synthase and calcitonin gene-related peptide $[17,18]$, but it is not known if they affect gland biogenesis.

\section{Salivary Gland Biogenesis}

The biogenesis of human salivary glands has been described from histological reports and was recently reviewed [19]. Briefly, the development of the major salivary glands in humans begins at around 6-8 weeks of gestation. The placodes of the major glands start as thickenings of the oral ectoderm. Salivary gland biogenesis is characterized by branching morphogenesis of epithelium, which is closely associated with the developing vasculature and nerves to form a branched glandular structure of ducts with terminal buds that become acini by around 14 weeks. The neural crest-derived mesenchyme provides growth fac- tors and other important molecular cues for epithelial branching morphogenesis. By 13-16 weeks in humans, the SMG appears well differentiated, with desmosome and microvillus projections from cells adjacent to the lumens. The basal lamina surrounds the epithelium, with a few elongated cells that appear similar to myoepithelial cells. The striated and intercalated ducts can be recognized as early as 16 weeks, with the acinar cells beginning to predominate the tissue by $20-24$ weeks. In humans, the salivary glands continue to develop up to 28 weeks, at which stage secretory products can be seen in acini. At birth the glands are functional to secrete saliva [19].

In humans there are genetic diseases affecting salivary glands that inform us about salivary gland biogenesis. Similar gene mutations have been generated in mice to learn more about the genetic and cellular mechanisms of gland development. For example, patients with hypohidrotic ectodermal dysplasia present clinically with defects in the teeth, hair, sweat glands and salivary glands. Hypohidrotic ectodermal dysplasia is caused by mutations in ectodysplasin-A, its receptor EDAR or EDARRAD, an intracellular signaling molecule [20]. These genes make proteins that function together during gland development and are critical for signaling between the salivary epithelium and mesenchyme. Importantly, genetic manipulation of the mouse genome enables the development of models to study the molecular mechanisms of hypohidrotic ectodermal dysplasia. Mice lacking EDAR have SMG aplasia or hypoplasia, which is caused by reduced SMG epithelial cell proliferation, lumen formation and histodifferentiation $[21,22]$. Other examples of genetic mutations in humans that cause problems with salivary biogenesis include patients with mutations in genes that affect fibroblast growth factor (FGF) signaling. Patients with a mutation or deletion of FGF10 have a syndrome called aplasia of lacrimal and salivary glands (OMIM180920). This syndrome results in salivary gland aplasia or hypoplasia, and the oral symptoms which present in childhood in- 
Fig. 3. There is a close association of the epithelium, nerves and blood vessels during SMG biogenesis. The projection of confocal sections shows immunostaining of the epithelium (blue), parasympathetic nerves (green) and blood vessels (red) of an E13 mouse SMG. The parasympathetic nerves are important for salivary gland biogenesis and regeneration.

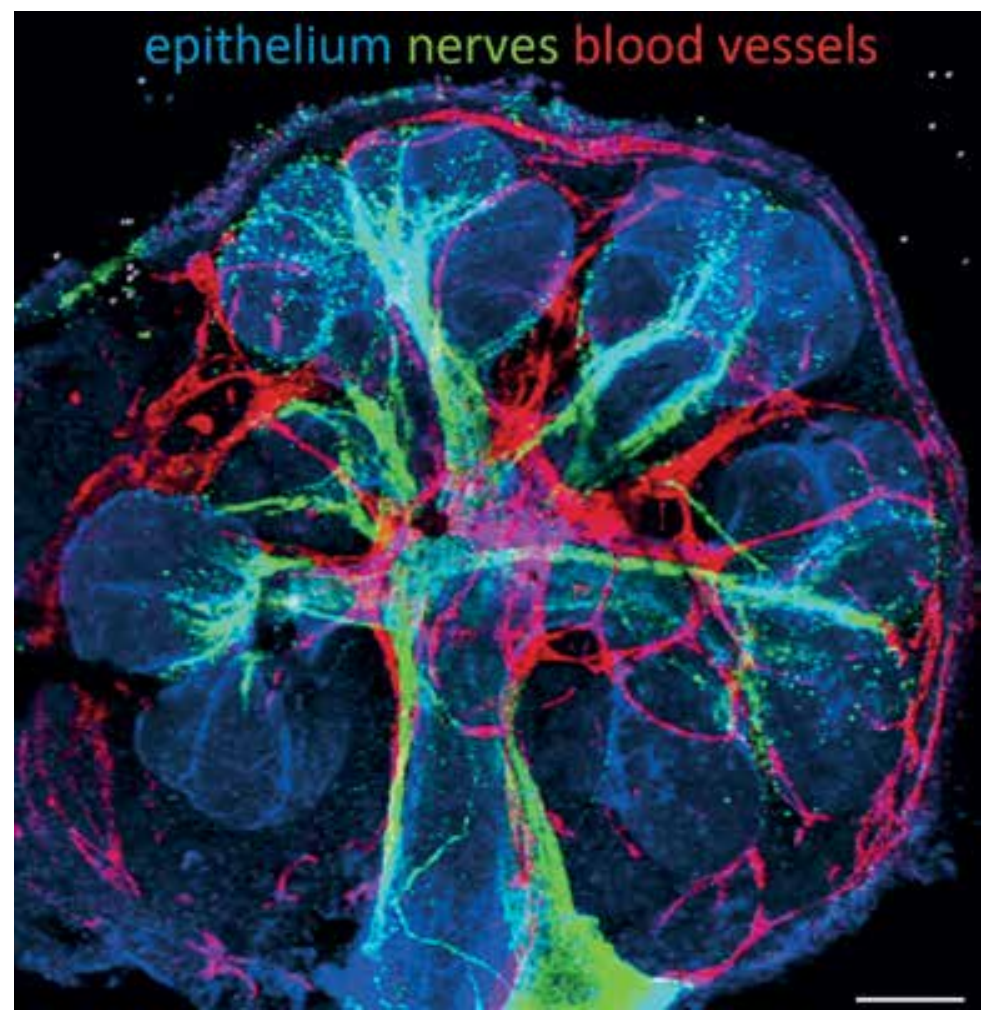

clude xerostomia, with increased dental erosion, caries, periodontal disease and oral infections [23]. A similar condition occurs in lacrimoauriculodentodigital (OMIM 149730) syndrome, which occurs due to mutations in FGF receptors and/or FGF10. This syndrome presents as aplasia and/or hypoplasia of the salivary and lacrimal glands, and also abnormalities of the ears, eyes, face, mouth, teeth, digits and genitourinary system. Again, mice with similar genetic mutations have similar defects in salivary gland biogenesis and have been used to study how FGF signaling affects gland biogenesis [24, 25].

In addition to mouse genetic studies, ex vivo culture of embryonic mouse SMGs is an important tool to investigate how cell and extracellular matrix (ECM) interactions coordinate salivary gland formation and function. The reader is directed to a number of detailed reviews on gland development $[16,21,26]$. Similar to human SMGs, the mouse SMG begins with the formation of a placode in the oral epithelium at embryonic day 11.5 (E11.5), which enlarges and invaginates into the surrounding mesenchyme alongside nerves and blood vessels (fig. 3). The signals that spatiotemporally regulate placode initiation in mouse salivary glands are not known. However, studies in Drosophila suggest that global patterning genes, such as scr, select the initiating site location [27, 28]. By E12, a primary end bud distal to the primary duct is formed, and branching morphogenesis begins on E13 with repeating rounds of proliferation and clefting of the end buds and formation of secondary ducts. The repetitive branching continues with duct lumen formation occurring, and by E16, the end bud cells start to polarize and acinar differentiation begins. The SMG is competent to secrete saliva at birth $[16,21,26]$. 
Salivary gland stem cells play an important role in the SMG biogenesis. A stem cell is defined as a cell capable of unlimited self-renewal and differentiation into all cell types of an adult gland. Stem cells differentiate along a lineage into more committed progenitor cells that lose their self-renewing ability and eventually become terminally differentiated. They have a high potential for proliferation and give rise to different cell types of a specific lineage. The difference between stem and progenitor cells in the SMG is currently not well defined, so here we use the term stem/progenitor cells. During mitosis, stem/progenitor cells divide to produce either 2 undifferentiated daughter clones, 2 more committed cells, or 1 undifferentiated clone and 1 more committed cell. Maintenance refers to cell division that gives rise to at least 1 daughter stem/progenitor cell so that the number of stem/progenitor cells is maintained with successive generations. During salivary gland biogenesis, stem/progenitor epithelial cell fates are defined and modulated by communication with the surrounding microenvironment or niche, which includes mesenchyme, blood vessels and nerves. Stem/progenitor cells respond to signaling factors, direct cell-cell contact, and by binding to niche-derived ECM.

The mesenchymal niche is instructive for the epithelial stem/progenitor cells during branching morphogenesis. Classic developmental biology experiments used ex vivo embryonic tissue recombination to show how tissue-specific mesenchyme provides instructive cues to guide the patterning and morphogenic potential of epithelial progenitor cells [29, 30]. Multiple molecules, including components of the ECM, cell adhesion receptors, proteases and growth factors, mediate these instructive interactions. For example, epithelia from lung, mammary, and pituitary gland develop into structures mimicking salivary glands when recombined with E13 salivary mesenchyme [31-34]. The converse is not true for SMG embryonic epithelia, whose growth was only induced by urogenital or SMG mesenchyme.
The role of the endothelial niche, i.e. blood vessels, in salivary gland biogenesis remains to be investigated, but is likely important, considering the essential endothelial-epithelial interactions in the organogenesis of the liver and pancreas $[35,36]$. Interstitial and immune cells, such as macrophages, may also have a role in gland biogenesis as has been shown for mammary gland development [37].

A major research goal is to identify and characterize the epithelial salivary gland stem/progenitor cells. Their location in adult glands is often described in relation to the main epithelial compartments of the gland: the ductal, acinar or myoepithelial cells. Stem/progenitor cells were initially identified as label-retaining cells because they were slowly dividing cells in the gland. In these experiments cells were pulse labeled with reagents that bind to DNA, and after months of continued growth only slowly dividing cells in the gland retained the DNA label. Initial studies showed that the label-retaining cells reside in the intercalated ducts and played a role in the regeneration of the gland after injury [38, 39]. Many studies have identified markers that can be used to isolate or label stem/ progenitor cell populations from adult mouse glands, including CD49f ( $\alpha_{6}$-integrin $)$, the tyrosine kinase receptor Kit, the transcription factor Ascl3, and the intracellular cytokeratin 5 (K5) [16,40-42]. Further study of the Kit-expressing cells also showed that this cell population is located in the ducts of the adult SMG [43]. In addition, stem/progenitor cells of the ducts that were activated in response to injury were shown to express markers Scal and Kit $[44,45], \alpha_{6} \beta_{1}$-integrin [46] or CD49f ( $\alpha_{6}$-integrin) and Thyl [47, 48]. Furthermore, Ascl3, a transcription factor, also marks a stem/progenitor population that is localized in the salivary ducts [49]. Interestingly, other stem/progenitor cells compensate for the genetic ablation of the Ascl3-expressing stem cell population in the SMG. One interpretation of this data is that multiple progenitor populations exist during biogenesis that can compensate for the absence of each other, although further work is required to support this hypothesis. 
The cytokeratins have been used extensively to study stem/progenitor cells in many epithelial organs. Basal cells expressing K5 and K14 (K5+K14+) label a population of stem/progenitor cells across different tissues, such as prostate, mammary gland and skin [50]. However in the salivary gland it appears these cytokeratins may label distinct progenitor cell populations. K5+ cells, which are mainly in the ductal structures, were shown to be a progenitor population in SMGs by genetic lineage tracing [14]. However, a significant finding was that the neuronal niche, i.e. the submandibular parasympathetic ganglion, which is present during SMG biogenesis, plays a critical role in the maintenance of these K5+ progenitors. Parasympathetic innervation and signaling via muscarinic receptors in the salivary epithelium, in combination with epithelial growth factor receptor signaling, maintained the K5+ cells during development and was critical for salivary gland biogenesis. More recently, a separate population of K14+ cells was shown to contain multipotent progenitors in SMGs [51]. The K14+ progenitors increase in cell number in response to Fgfr2b and Kit signaling and are located in the salivary gland end buds during biogenesis. Furthermore, epithelial Kit+ cells in the end buds produce neurotrophic factors, such as neurturin (Nrtn), which promote parasympathetic nerve survival and axon extension [15]. These parasympathetic nerves produce acetylcholine and further signal to the K5+ cells in the duct to continue to grow and differentiate. In sum, the different epithelial cells and their niches coordinate branching morphogenesis and gland biogenesis $[14,15]$. These data have significant therapeutic implications in terms of repairing or regenerating adult salivary tissue.

\section{Regeneration of Salivary Glands}

The goal of regenerative medicine is to restore gland function in patients who suffer from irreversible loss of salivary gland function follow- ing resection of salivary tumors and therapeutic radiation of head and neck cancers. Additionally, patients suffer from gland hypofunction in diseases affecting salivary glands, such as Sjögren's syndrome, which is an autoimmune disease that results in inflammatory-mediated damage [52, 53]. A major research focus has been to regenerate salivary glands after radiation damage, because head and neck carcinoma is the sixth most common cancer in the world and affects tens of thousands of new patients every year. With irradiation being a primary treatment option, and the salivary glands often lying in the field of radiation, the subsequent salivary gland damage and xerostomia, or dry mouth, are significant causes of morbidity in these patients [54]. Modern advances in radiation therapy, such as intensity-modulated radiotherapy, allow for organ-sparing techniques; however, there are insufficient randomized clinical trials on intensity-modulated radiotherapy and no data to show that intensity-modulated radiotherapy reduces SMG radiation dosage [55]. Current treatment options for radiation-induced xerostomia include the use of saliva substitutes or parasympathetic agonists, such as pilocarpine, to stimulate salivary flow. However, there are problems with side effects of systemic parasympathomimetics, and along with their variable efficacy, this means more permanent treatment options are required. Clinical trials in patients treated with radiation therapy studied the effect of amifostine, an oxygen free radical scavenger, on postirradiation salivary gland damage. They showed a reduction in late xerostomia in patients on amifostine [56]. Also, in studies in rats, preirradiation stimulation of muscarinic acetylcholine receptors reduced parotid gland damage [57].

The study of mouse salivary glands provides mechanistic insight for developing new therapies for human salivary gland hypofunction. Salivary gland regeneration has the potential to permanently restore salivary gland secretory function in 


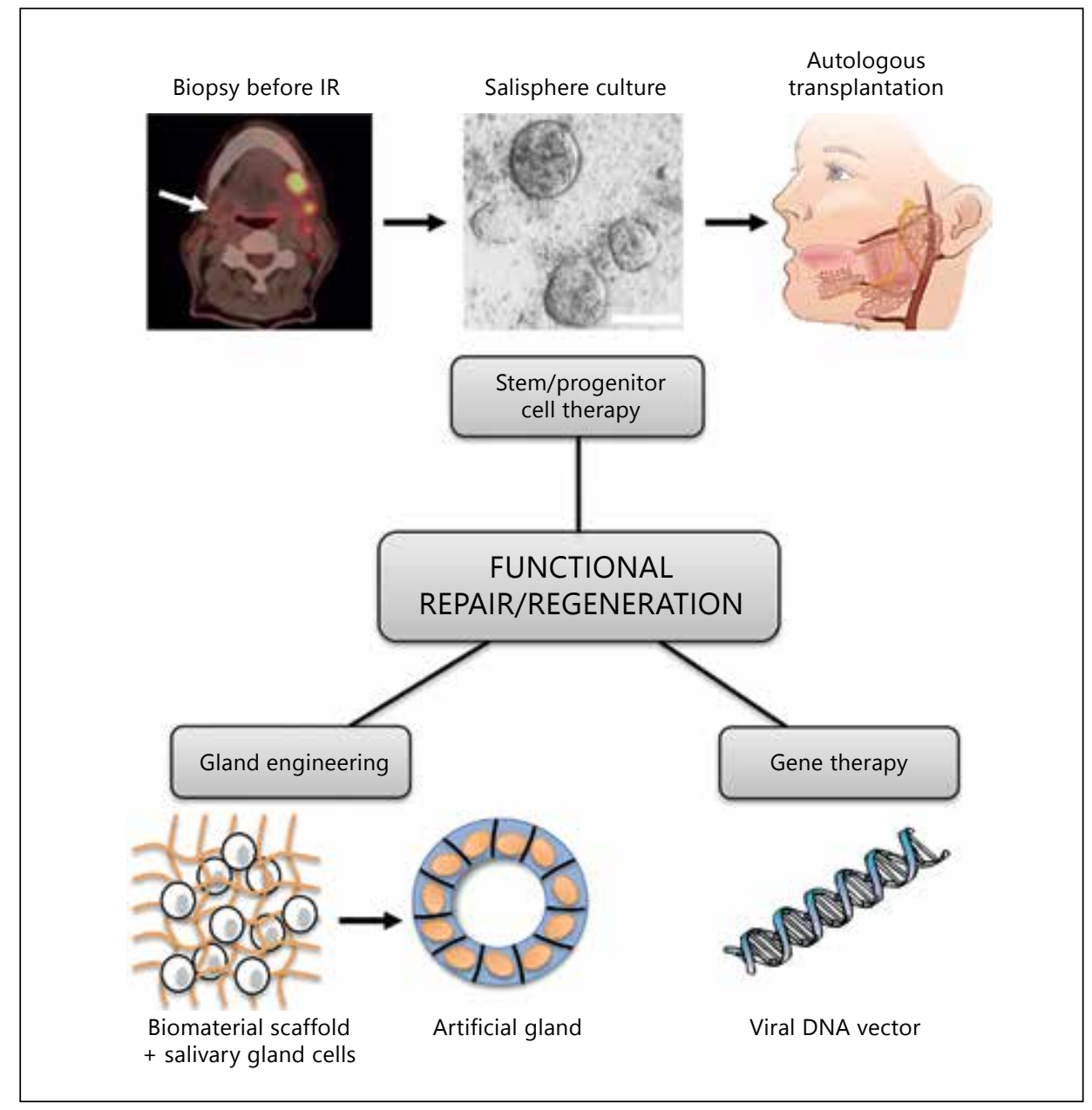

Fig. 4. Overview of three approaches for salivary gland repair or regeneration: stem/progenitor cell therapy, gene therapy and gland bioengineering. IR = Irradiation. For stem/progenitor cell therapy, a preoperative PET/CT scan, adapted from Nahmias et al. [77], shows the region of the unaffected SMG (arrow) used for a biopsy and the affected submandibular lymph nodes are yellow. Human salispheres are cultured from the biopsy; scale bar $=100 \mu \mathrm{m}$. Autologous transplantation of the spheres into the affected salivary gland occurs after therapy. Gland bioengineering involves combining biomaterials with cells to grow an artificial gland, which can be transplanted into a patient. Gene therapy uses viral vectors to transduce genes that repair or improve the secretory function of the gland.

patients with hyposalivation to improve their oral health and quality of life. The three main approaches that have been proposed are (1) gene therapy, by using viral vectors, (2) stem/progenitor cell-based therapy and (3) replacement with a bioengineered gland (fig. 4) [58]. In the following sections we will review these regenerative approaches.

Recently, pioneering gene therapy trials were completed in patients suffering from radiationinduced salivary hypofunction. The technique used the retroductal injection of an adenovirus 
that expressed a water channel (AQP1) to transduce the remaining ductal epithelium to secrete fluid. This trial was the culmination of many years of preclinical studies of gene transfer using rodents, minipigs and primates to develop the technique before translation to human clinical trials [59-62]. Aquaporins are water channels important for transcellular water transport in salivary glands, and human AQP1 gene transfer was shown to be efficacious in nonhuman in vivo models [61]. Recent results from the phase I clinical trial showed no deaths, serious adverse events or dose-limiting toxicities. Objective and subjective restoration of salivary gland function was reported in some of the patients who received the AdhAQP1 vector [60]. Future studies to improve viral vectors and optimize the vector dose may improve the clinical outcome. However, the effect of irradiation on the microenvironment or niche, including the extracellular matrix, endothelial, neuronal and stromal cells, is not fully understood. Complete functional regeneration requires restoration of all tissue types, which may not occur by gene therapy alone.

Cell-based therapies could ideally use a patient's own cells to regenerate tissues in organ systems. A common example in patients today is bone marrow allotransplants to replace and regenerate the hematopoietic system in patients with diseases such as aplastic anemia or leukemia. This technique was also used by the Coppes group to treat salivary gland hypofunction in mice [63]. They used bone marrow stem cells to regenerate irradiated mouse SMGs and showed an increase in salivary secretion after mobilization of bone marrow stem cells in the irradiated tissue. The transplanted cells were not found to be part of the epithelial compartment of the gland, but potentially secreted a paracrine acting factor that stimulated regeneration of the epithelia [63]. Consequently, others have taken this approach by showing that a potential proregenerative paracrine acting factor can be derived from bone marrow cells. They demonstrated this paracrine effect by using a bone marrow stem cell supernatant or 'bone marrow soup', which was as effective as whole live bone marrow cells for repairing irradiated salivary glands [64]. They showed that the bone marrow-derived factors not only restored secretory function, but also protected cells, increased vascularity, and upregulated genes important for regeneration, e.g. genes for BMP7, EGF, NGF, MMP2, and cyclin $\mathrm{D}_{1}$. These data lead to the logical suggestion that paracrine factors may be able to repair or stimulate the irradiated niche to stimulate surviving salivary gland stem/ progenitor cells to regenerate functional salivary tissue.

A major advance in the field came from the Coppes laboratory which showed that the transplantation of adult mouse Kit+ cells resulted in functional regeneration of the salivary gland epithelium, which demonstrated that cell therapy in irradiated SMGs was a viable approach for regeneration $[65,66]$. They have also shown that human salivary glands have cells with the same regenerative capacity, expressing Kit and capable of in vitro differentiation and self-renewal [67]. Autologous transplantation would involve a biopsy from a patient's own salivary gland before irradiation therapy, being used to culture, expand and maintain the stem/progenitor cells, which would be transplanted into the salivary gland stroma after radiation treatment. This model is the basis for ongoing studies to better understand adult salivary gland stem/progenitor cell populations and the signaling pathways important for maintaining their cell fate and expanding their number in culture.

It was previously shown that autonomic innervation of the salivary gland is required for salivary gland repair after atrophy [13]. In line with this reasoning, the role of parasympathetic innervation maintaining $\mathrm{K} 5$ progenitor cells during SMG biogenesis [14] leads one to ask what factors support the nerves during development, and whether these factors could be used to repair and support the function of nerves after irradiation 
damage. Nrtn is a neurotrophic factor expressed by salivary epithelium that binds to its receptor, GFR- $\alpha_{2}$, on parasympathetic nerves to signal via RET, a tyrosine kinase coreceptor, and Src kinase [15]. Nrtn was shown to reduce neuronal apoptosis after irradiation, restore parasympathetic function and improve epithelial regeneration in a mouse ex vivo model [15]. Furthermore, adult human salivary glands damaged by irradiation were analyzed and shown to have reduced parasympathetic innervation. Therefore, it is possible that neurotrophic factors such as Nrtn will protect the parasympathetic nerves from irradiation damage and subsequently improve epithelial regeneration.

The concept of providing factors to protect or support the neuronal niche would also suggest that further investigations of sympathetic signaling and the role of Schwann cells are warranted to guide regeneration. Sympathetic nerve function was retained after irradiation in rats, suggesting irradiation affected the acinar response to stimulation, but not the sympathetic nerves themselves [68]. The difference in how irradiation affects sympathetic and parasympathetic nerves is not well understood, and in fact it may be the balance between the two that is important. Furthermore, Schwann cells have been shown to play critical roles in nerve development and survival [69] and may be important to protect nerves from irradiation damage. Understanding how nerves are affected by irradiation and how they might instruct or direct stem/progenitor cells to regenerate gland architecture will be important for cellbased or gland engineering approaches to regeneration.

The tissue engineering field aims to use biomaterials and cells to replace missing or damaged tissues. The field has evolved to understand the important role of the ECM environment for proper tissue regeneration. The ECM provides cues for cell function, stem cell self-renewal and differentiation, and dynamic remodeling necessary for engineering of complex tissues [70].
Models to engineer functional salivary gland tissue for autotransplantation and functional regeneration have been proposed. Engineering of an 'artificial' salivary gland may involve the use of synthetic or ECM-derived 3-dimensional scaffolds onto which cells are seeded to form a polarized secretory epithelium $[71,72]$. Three-dimensional synthetic and ECM-based scaffolds can be used to culture and differentiate tissue-specific progenitor cell populations into composite glandular structures, with acinar, ductal, nerve and vascular components.

ECM components, such as laminin and glycosaminoglycans, attached to nanofiber scaffolds are important for regulating salivary gland epithelial cell proliferation and polarity [73]. ECMbased biomaterials are important for facilitating and regulating repair and regeneration of salivary glands by promoting membrane polarization. Cultured acinar cell populations formed lobular structures mimicking intact glands with functional activity, marked by $\alpha$-amylase and Aqp5 expression when cultured on Matrigel or a 3-dimensional hydrogel containing a perlecan-derived bioactive peptide [74]. Furthermore, these cultures form 3-dimensional spheroids in hyaluronic acid-based hydrogels after long-term culture and respond to neurotransmitters for salivary protein secretion [75]. The surface architecture of a scaffold also influencescell differentiation. By fabricating a surface micropatterned with 'craters' lined with nanofibers of polylactic-coglycolic acid that mimicked the basement membrane of salivary acini, it was demonstrated that increased crater curvature promoted differentiation of salivary gland cells [76].

Translating these bioengineering approaches to human clinical trials is the next goal. Following in the footsteps of the pioneering work to translate gene therapy to the clinic, cell-based and/or tissue engineering approaches will require validation in nonhuman models to demonstrate their safety and efficacy. The clinical success of salivary gland regeneration may also require support of 
the stroma, nerves, vasculature and immune system. Engineering and clinical/translational investigations must be informed by the advancing knowledge in stem cell biology and salivary gland development, requiring a multidisciplinary approach with biologists, engineers and clinicians. Salivary gland biology provides a unique system to study biogenesis and regeneration, which will hopefully one day restore salivary gland function in patients who suffer from xerostomia.

\section{Acknowledgments}

We would like to thank Dr. I.M. Lombaert and Dr. W.M. Knosp for discussions and critical reading of this paper and S.E. Kibbey for illustration assistance. K.V.H. and M.P.H. are supported by the Intramural Research Program of the National Institute of Dental and Craniofacial Research, NIH, and K.V.H. is supported by the NIH Medical Research Scholars Program.

\section{References}

1 Carlson GW: The salivary glands: embryology, anatomy, and surgical applications. Surg Clin North Am 2000;80:261273

12 Johns ME: Salivary-glands - anatomy and embryology. Otolaryngol Clin North Am 1977;10:261-271.

3 Ten Cate AR: Oral Histology: Development, Structure, and Function, ed 5. St Louis, Mosby, 1998.

-4 Ferreira JN, Hoffman MP: Interactions between developing nerves and salivary glands. Organogenesis 2013;9:199-205.

$\checkmark 5$ Davis RA, Anson BJ, Budinger JM, Kurth LR: Surgical anatomy of the facial nerve and parotid gland based upon a study of 350 cervicofacial halves. Surg Gynecol Obstet 1956;102:385-412.

6 Frommer J: Human accessory parotidgland - its incidence, nature, and significance. Oral Surg Oral Med Oral Pathol Oral Radiol Endodont 1977;43: 671-676.

7 Ishizuka K, Oskutyte D, Satoh Y, Murakami T: Multi-source inputs converge on the superior salivatory nucleus neurons in anaesthetized rats. Auton Neurosci 2010;156:104-110.

8 Kahle W, Frotscher M: Color Atlas of Human Anatomy - Nervous System and Sensory Organs, ed 1. Stuttgart, Thieme, 2003

-9 Tosios KI, Nikolakis M, Prigkos AC, Diamanti S, Sklavounou A: Nerve cell bodies and small ganglia in the connective tissue stroma of human submandib ular glands. Neurosci Lett 2010;475: 53-55.
10 Geerling G, Garrett JR, Paterson KL, Sieg P, Collin JR, Carpenter GH, Hakim SG, Lauer I, Proctor GB: Innervation and secretory function of transplanted human submandibular salivary glands. Transplantation 2008;85:135-140.

11 Mathison R, Davison JS, Befus AD: Neuroendocrine regulation of inflammation and tissue repair by submandibular gland factors. Immunol Today 1994;15: 527-532.

12 Savastano LE, Castro AE, Fitt MR, Rath MF, Romeo HE, Munoz EM: A standardized surgical technique for rat superior cervical ganglionectomy. J Neurosci Methods 2010;192:22-33.

13 Proctor GB, Carpenter GH: Regulation of salivary gland function by autonomic nerves. Auton Neurosci Basic Clin 2007; 133:3-18.

$>14$ Knox SM, Lombaert IMA, Reed X, Vitale-Cross L, Gutkind JS, Hoffman MP: Parasympathetic innervation maintains epithelial progenitor cells during salivary organogenesis. Science 2010;329: 1645-1647.

15 Knox SM, Lombaert IMA, Haddox CL, Abrams SR, Cotrim A, Wilson AJ, Hoffman MP: Parasympathetic stimulation improves epithelial organ regeneration. Nat Commun 2013;4:1494.

$\checkmark 16$ Knosp WM, Knox SM, Hoffman MP: Salivary gland organogenesis. Wiley Interdisc Rev Dev Biol 2012;1:69-82.

17 Ekstrom J, Garrett JR, Mansson B, Rowley PS, Tobin G: Depletion of large dense-cored vesicles from parasympathetic nerve terminals in rat parotid glands after prolonged stimulation of the auriculotemporal nerve. Regul Pept 1989;25:61-67.
18 Ekstrom J: Role of nonadrenergic, noncholinergic autonomic transmitters in salivary glandular activities in vivo; in Garrett JR, Ekstrom J, Anderson LC (eds): Neural Mechanisms of Salivary Secretion. Basel, Karger, 1999, vol 6, pp 94-130.

19 Knox S, Hoffman MP: Salivary Gland Development. Ames, Blackwell Publications, 2008.

20 Mikkola ML: Molecular aspects of hypohidrotic ectodermal dysplasia. Am J Med Genet A 2009;149A:2031-2036.

21 Tucker AS: Salivary gland development. Semin Cell Dev Biol 2007;18:237-244.

-22 Jaskoll T, Zhou YM, Trump G, Melnick M: Ectodysplasin receptor-mediated signaling is essential for embryonic submandibular salivary gland development. Anat Rec A Discov Mol Cell Evol Biol 2003;271A:322-331.

23 Entesarian M, Matsson H, Klar J, Bergendal B, Olson L, Arakaki R, Hayashi Y, Ohuchi H, Falahat B, Bolstad AI, Jonsson R, Wahren-Herlenius M, Dahl N: Mutations in the gene encoding fibroblast growth factor 10 are associated with aplasia of lacrimal and salivary glands. Nat Genet 2005;37:125-127.

24 De Moerlooze L, Spencer-Dene B, Revest J, Hajihosseini M, Rosewell I, Dickson C: An important role for the IIIb isoform of fibroblast growth factor receptor 2 (FGFR2) in mesenchymalepithelial signalling during mouse organogenesis. Development 2000;127: 483-492. 
25 Jaskoll T, Abichaker G, Witcher D, Sala FG, Bellusci S, Hajihosseini MK, Melnick M: FGF10/FGFR2b signaling plays essential roles during in vivo embryonic submandibular salivary gland morphogenesis. BMC Dev Biol 2005;5:11.

-26 Patel VN, Rebustini IT, Hoffman MP: Salivary gland branching morphogenesis. Differentiation 2006;74:349-364.

27 Kerman BE, Cheshire AM, Andrew DJ: From fate to function: the Drosophila trachea and salivary gland as models for tubulogenesis. Differentiation 2006;74: 326-348.

28 Denny PC, Ball WD, Redman RS: Salivary glands: a paradigm for diversity of gland development. Crit Rev Oral Biol Med 1997;8:51-75.

29 Grobstein C: Trans-filter induction of tubules in mouse metanephrogenic mesenchyme. Exp Cell Res 1956;10: 424-440.

30 Kusakabe M, Sakakura T, Sano M, Nishizuka Y: A pituitary-salivary mixed gland induced by tissue recombination of embryonic pituitary epithelium and embryonic submandibular gland mesenchyme in mice. Dev Biol 1985;110: 382-391.

-31 Kratochwil K: Organ specificity in mesenchymal induction demonstrated in the embryonic development of the mammary gland of the mouse. Dev Biol 1969;20:46-71.

32 Sakakura T, Nishizuka Y, Dawe CJ: Mesenchyme-dependent morphogenesis and epithelium-specific cytodifferentiation in mouse mammary gland. Science 1976;194:1439-1441.

33 Nogawa H: Determination of the curvature of epithelial cell mass by mesenchyme in branching morphogenesis of mouse salivary gland. J Embryol Exp Morphol 1983;73:221-232.

34 Nogawa H, Mizuno T: Mesenchymal control over elongating and branching morphogenesis in salivary gland development. J Embryol Exp Morphol 1981; 66:209-221.

35 Loreto C, Caltabiano R, Musumeci G, Caltabiano C, Greco MG, Leonardi R: Hepatocyte growth factor receptor, cmet, in human embryo salivary glands. An immunohistochemical study. Anat Histol Embryol 2010;39:173-177.

36 Matsumoto K, Yoshitomi H, Rossant J, Zaret KS: Liver organogenesis promoted by endothelial cells prior to vascular function. Science 2001;294:559-563.
37 Wynn TA, Chawla A, Pollard JW: Macrophage biology in development, homeostasis and disease. Nature 2013;496: 445-455.

38 Carpenter GH, Khosravani N, Ekstrom J, Osailan SM, Paterson KP, Proctor GB: Altered plasticity of the parasympathetic innervation in the recovering rat submandibular gland following extensive atrophy. Exp Physiol 2009;94:213-219.

39 Denny PC, Liu PX, Denny PA: Evidence of a phenotypically determined ductal cell lineage in mouse salivary glands. Anat Rec 1999;256:84-90.

40 Lombaert IMA, Hoffman MP: Epithelial stem/progenitor cells in the embryonic mouse submandibular gland; in Tucker AS, Miletich I (eds): Salivary Glands: Development, Adaptations and Disease. Front Oral Biol. Basel, Karger, 2010, vol 14, pp 90-106.

41 Lombaert IMA, Hoffman MP: Epithelial stem/progenitor cells in the embryonic mouse submandibular gland; in Tucker AS, Miletich I (eds): Salivary Glands: Development, Adaptations and Disease. Front Oral Biol. Basel, Karger, 2010, vol 14, pp 90-106.

42 Lombaert IMA, Hoffman MP: Stem cells in salivary gland development and regeneration; in Huang GTJ, Thesleff I (eds): Stem Cells in Craniofacial Development and Regeneration. Hoboken, Wiley \& Sons, 2013, pp 271-284.

43 Coppes RP, Stokman MA: Stem cells and the repair of radiation-induced salivary gland damage. Oral Dis 2011;17: 143-153.

44 Hisatomi Y, Okumura K, Nakamura K, Matsumoto S, Satoh A, Nagano K, Yamamoto T, Endo F: Flow cytometric isolation of endodermal progenitors from mouse salivary gland differentiate into hepatic and pancreatic lineages. Hepatology 2004;39:667-675.

45 Okumura K, Nakamura K, Hisatomi Y, Nagano K, Tanaka Y, Terada K, Sugiyama T, Umeyama K, Matsumoto K, Yamamoto T, Endo F: Salivary gland progenitor cells induced by duct ligation differentiate into hepatic and pancreatic lineages. Hepatology 2003;38:104-113.

46 David R, Shai E, Aframian DJ, Palmon A: Isolation and cultivation of integrin alpha(6)beta(1)-expressing salivary gland graft cells: a model for use with an artificial salivary gland. Tissue Eng A 2008;14:331-337.
47 Matsumoto S, Okumura K, Ogata A, Hisatomi Y, Sato A, Hattori K, Matsumoto M, Kaji Y, Takahashi M, Yamamoto T, Nakamura K, Endo F: Isolation of tissue progenitor cells from duct-ligated salivary glands of swine. Cloning Stem Cells 2007;9:176-190.

48 Sato A, Okumura K, Matsumoto S, Hattori K, Hattori S, Shinohara M, Endo F: Isolation, tissue localization, and cellular characterization of progenitors derived from adult human salivary glands. Cloning Stem Cells 2007;9:191-205.

-49 Yoshida S, Ohbo K, Takakura A, Takebayashi H, Okada T, Abe K, Nabeshima Y: Sgn1, a basic helix-loop-helix transcription factor, delineates the salivary gland duct cell lineage in mice. Dev Biol 2001;240:517-530.

50 Purkis PE, Steel JB, Mackenzie IC, Nathrath WB, Leigh IM, Lane EB: Antibody markers of basal cells in complex epithelia. J Cell Sci 1990;97:39-50.

51 Lombaert IM, Abrams SR, Li L, Eswarakumar VP, Sethi AJ, Witt RL, Hoffman MP: Combined Kit and FGFR2b signaling regulates epithelial progenitor expansion during organogenesis. Stem Cell Rep 2013;1:604-619.

52 Kok MR, Yamano S, Lodde BM, Wang JH, Couwenhoven RI, Yakar S, Voutetakis A, Leroith D, Schmidt M, Afione S, Pillemer SR, Tsutsui MT, Tak PP, Chiorini JA, Baum BJ: Local adeno-associated virus-mediated interleukin 10 gene transfer has disease-modifying effects in a murine model of Sjögren's syndrome. Hum Gene Ther 2003;14:1605-1618.

53 Vitali C, Bombardieri S, Moutsopoulos HM, Balestrieri G, Bencivelli W, Bernstein RM, Bjerrum KB, Braga S, Coll JQ, Devita S, Drosos AA, Ehrenfeld M, Hatron PY, Hay EM, Isenberg DA, Janin A, Kalden JR, Kater L, Konttinen YT, Maddison PJ, Maini RN, Manthorpe R, Meyer O, Ostuni P, Pennec Y, Prause JU, Richards A, Sauvezie B, Schiodt M, Sciuto M, Scully C, Shoenfeld Y, Skopouli FN, Smolen JS, Snaith ML, Tishler M, Todesco S, Valesini G, Venables PJW, Wattiaux EJ, Youinou P: Preliminary criteria for the classification of Sjögren's syndrome - results of a prospective concerted action supported by the European Community. Arthritis Rheum 1993;36:340-347.

54 Dirix P, Nuyts S, Van den Bogaert W: Radiation-induced xerostomia in patients with head and neck cancer - a literature review. Cancer 2006;107: 2525-2534. 
-55 O'Sullivan B, Rumble RB, Warde P: Intensity-modulated radiotherapy in the treatment of head and neck cancer. Clin Oncol 2012;24:474-487.

56 Epstein JB, Thariat J, Bensadoun R-J, Barasch A, Murphy BA, Kolnick L, Popplewell L, Maghami E: Oral complications of cancer and cancer therapy. Cancer J Clin 2012;62:400-422.

57 Coppes RP, Zeilstra LJW, Kampinga $\mathrm{HH}$, Konings AWT: Early to late sparing of radiation damage to the parotid gland by adrenergic and muscarinic receptor agonists. Br J Cancer 2001;85:10551063.

58 Redman RS: On approaches to the functional restoration of salivary glands damaged by radiation therapy for head and neck cancer, with a review of related aspects of salivary gland morphology and development. Biotech Histochem 2008;83:103-130.

59 Mastrangeli A, O'Connell B, Aladib W, Fox PC, Baum BJ, Crystal RG: Direct in vivo adenovirus-mediated gene transfer to salivary glands. Am J Physiol 1994; 266:G1146-G1155.

60 Baum BJ, Alevizos I, Zheng C, Cotrim AP, Liu S, McCullagh L, Goldsmith CM, Burbelo PD, Citrin DE, Mitchell JB, Nottingham LK, Rudy SF, Van Waes C, Whatley MA, Brahim JS, Chiorini JA, Danielides S, Turner RJ, Patronas NJ, Chen CC, Nikolov NP, Illei GG: Early responses to adenoviral-mediated transfer of the aquaporin-1 cDNA for radiation-induced salivary hypofunction. Proc Natl Acad Sci 2012;109:1940319407.

61 Shan Z, Li J, Zheng C, Liu X, Fan Z, Zhang C, Goldsmith CM, Wellner RB, Baum BJ, Wang S: Increased fluid secretion after adenoviral-mediated transfer of the human aquaporin-1 cDNA to irradiated miniature pig parotid glands. Mol Ther 2005;11:444-451.
62 Zheng C, Cotrim AP, Rowzee A, Swaim W, Sowers A, Mitchell JB, Baum BJ: Prevention of radiation-induced salivary hypofunction following HKGF gene delivery to murine submandibular glands. Clin Cancer Res 2011;17:2842-2851.

63 Lombaert IM, Wierenga PK, Kok T, Kampinga HH, de Haan G, Coppes RP: Mobilization of bone marrow stem cells by granulocyte colony-stimulating factor ameliorates radiation-induced damage to salivary glands. Clin Cancer Res 2006;12:1804-1812.

64 Tran SD, Liu Y, Xia D, Maria OM, Khalili S, Wang RW-J, Quan V-H, Hu S, Seuntjens J: Paracrine effects of bone marrow soup restore organ function, regeneration, and repair in salivary glands damaged by irradiation. PloS One 2013;8:e61632.

65 Lombaert IMA, Brunsting JF, Wierenga PK, Faber H, Stokman MA, Kok T, Visser WH, Kampinga HH, de Haan G, Coppes RP: Rescue of salivary gland function after stem cell transplantation in irradiated glands. Plos One 2008;3: e2063.

66 Nanduri LSY, Maimets M, Pringle SA, van der Zwaag M, van Os RP, Coppes RP: Regeneration of irradiated salivary glands with stem cell marker expressing cells. Radiother Oncol 2011;99:367-372.

67 Feng JL, van der Zwaag M, Stokman MA, van Os R, Coppes RP: Isolation and characterization of human salivary gland cells for stem cell transplantation to reduce radiation-induced hyposalivation. Radiother Oncol 2009;92:466-471.

68 Kohn WG, Grossman E, Fox PC, Armando I, Goldstein DS, Baum BJ: Effect of ionizing-radiation on sympatheticnerve function in rat parotid-glands. J Oral Pathol Med 1992;21:134-137.

69 Yamaguchi Y, Yonemura S, Takada S: Grainyhead-related transcription factor is required for duct maturation in the salivary gland and the kidney of the mouse. Development 2006; 133:47374748 .
70 Daley WP, Peters SB, Larsen M: Extracellular matrix dynamics in development and regenerative medicine. J Cell Sci 2008;121:255-264.

71 Tran SD, Sugito T, Dipasquale G, Cotrim AP, Bandyopadhyay BC, Riddle K, Mooney D, Kok MR, Chiorini JA, Baum BJ: Re-engineering primary epithelial cells from rhesus monkey parotid glands for use in developing an artificial salivary gland. Tissue Eng 2006;12:29392948.

72 Sun T, Zhu J, Yang X, Wang S: Growth of miniature pig parotid cells on biomaterials in vitro. Arch Oral Biol 2006;51: 351-358.

73 Cantara SI, Soscia DA, Sequeira SJ, JeanGilles RP, Castracane J, Larsen M: Selective functionalization of nanofiber scaffolds to regulate salivary gland epithelial cell proliferation and polarity. Biomaterials 2012;33:8372-8382.

74 Pradhan S, Zhang C, Jia X, Carson DD, Witt R, Farach-Carson MC: Perlecan domain IV peptide stimulates salivary gland cell assembly in vitro. Tissue Eng A 2009;15:3309-3320.

75 Pradhan-Bhatt S, Harrington DA, Duncan RL, Jia X, Witt RL, Farach-Carson MCP: Implantable three-dimensional salivary spheroid assemblies demonstrate fluid and protein secretory responses to neurotransmitters. Tissue Eng A 2013;26:26.

76 Soscia DA, Sequeira SJ, Schramm RA, Jayarathanam K, Cantara SI, Larsen M, Castracane J: Salivary gland cell differentiation and organization on micropatterned PLGA nanofiber craters. Biomaterials 2013;34:6773-6784.

77 Nahmias C, Carlson ER, Duncan LD, Blodgett TM, Kennedy J, Long MJ, Carr C, Hubner KF, Townsend DW: Positron emission tomography/computerized tomography (PET/CT) scanning for preoperative staging of patients with oral/ head and neck cancer. J Oral Maxillofac Surg 2007;65:2524-2535.
Matthew P. Hoffman

NIDCR, NIH, Bldg 30/Rm 433

30 Convent Drive, MSC 4370

Bethesda, MD 20892-4370 (USA)

E-Mail mhoffman@mail.nih.gov 